\title{
"transportando fortunas para povoar deserta e inculta campanha": brasileiros e produção pecuária no norte do uruguai em meados do século $x^{*}{ }^{\star}$
}

\section{"transporting fortunes to populate a desert and uncultivated campaign": brazilians and livestock production in northern uruguay in the mid-19th century}

\author{
Carla Menegat ${ }^{\star} \star$ \\ Instituto Federal de Educação, Ciência e Tecnologia Sul-Rio-Grandense, Gravataí, Rio Grande \\ do Sul, Brasil
}

\section{RESUMO}

Em 1850 o governo imperial brasileiro, através de suas autoridades militares na fronteira da Província do Rio Grande do Sul com o Estado Oriental do Uruguai, listou 1.353 propriedades pertencentes a brasileiros no país vizinho. À produção dessa lista, seguiu-se a intervenção militar conhecida como Campanha contra Oribe e Rosas, que levaria ao fim da Guerra Grande no Uruguai em 1851 e à assinatura de uma série de cinco tratados entre os dois países que privilegiariam os pecuaristas brasileiros estabelecidos na campanha norte oriental. Observando essa lista como parte de uma relação entre produtores de gado brasileiros residentes no Uruguai, autoridades daquele país e do Império, o objetivo da pesquisa a ser apresentada foi discutir o impacto da presença desses pecuaristas no país vizinho, em termos da constituição de redes de comércio e produção.

Palavras-chave: Rio de La Plata. Pecuária. Brasil Império.

\section{Abstract}

In 1850 the Brazilian imperial government, through its military authorities on the border of the Province of Rio Grande do Sul with the Eastern State of Uruguay, listed 1.353 properties owned by Brazilians in the neighboring country. The production of this list was followed by the military intervention known as the Campaign against Oribe and Rosas, which would lead to the end of the Guerra Grande in Uruguay in 1851 and the signing of a series of five treaties between the two countries that would favor Brazilian cattle ranchers established in north countryside. Observing this list as part of a relationship between Brazilian cattle producers resident in Uruguay, authorities of that country and Brazil, the objective of the research to be presented was to discuss the impact of the presence of these ranchers in the neighboring country, in terms of the constitution of networks of trade and production.

Keywords: Rio de La Plata. Livestock. Imperial Brasil.

* Submissão: 19/01/2019; aprovação: 15/11/2019.

$\star \star$ Professora do Instituto Federal de Educação, Ciência e Tecnologia Sul-Rio-Grandense.E-mail: carlamenegat@gmail.com.ORCID:<https://orcid.org/0000-00017602-6416>. 
Em 1853 o alcaide da Villa de Melo enviou nota ao Ministério de Governo uruguaio manifestando a impossibilidade de eleger as autoridades departamentais de Aceguá devido à ausência de cidadãos orientais naquele partido.A situação era agravada pela negativa dos brasileiros que ali viviam de serem arrolados nos padrões e censos do Estado Oriental (Borucki; Chagas; Stalla, 2004, p. 162). Ao se manterem alheios às estatísticas e registros daquele Estado, os brasileiros acreditavam poder manter-se como se estivessem no território do Império. As implicações desse tipo de prática impactaram a relação que esses súditos imperiais estabeleceram com o Estado Imperial em meados do século XIX.

A ocupação da metade norte da atual República Oriental do Uruguai por luso-brasileiros remonta ao fim do período colonial e marca a própria conformação da espacialidade da região. A fonte mais utilizada pela historiografia (Souza; Prado, 2004) para estudar os proprietários brasileiros estabelecidos no Uruguai tem sido o Relatório da Repartição de Negócios Estrangeiros (RRNE), do ano de 1850. No anexo A do relatório constam quinze listas, distribuídas em documentos e envios diferentes e produzidas pelos Comandos Militares da Fronteira com a relação dos brasileiros e suas propriedades e extensões no país vizinho. Juntar essas listas, tão distintas na sua configuração, para realizar uma análise que busque entender o conjunto dos estancieiros exige cuidados. Para tanto, optei por confrontar e completar os dados da lista com outro conjunto documental que reflete a situação do patrimônio dos brasileiros no Estado Oriental: os inventários post-mortem ${ }^{1}$. O objetivo foi, a partir de vestígios produzidos em contextos distintos, observar a forma como esses sujeitos ocuparam esse território, estabelecendo um quadro no qual seja possível visualizar como suas atividades produtivas se organizavam.

O contexto de produção dos inventários post-mortem implica o desejo dos herdeiros, de seus responsáveis ou de seus credores, de recorrerem de alguma forma ao Estado imperial no sentido de ele garantir o justo

\footnotetext{
Sobre a amostra de inventários post-mortem que contribuem com a análise realizada aqui, preciso também realizar algumas considerações. Foram consultados 1.042 processos das Comarcas de Piratini - que incluía a vila de Jaguarão - Pelotas, Rio Grande, Bagé, Santana do Livramento e Alegrete, no período entre 1835 e 1870, depositados no Arquivo Público do Estado do Rio Grande do Sul. Desses processos, 12\%, ou seja, 126 apresentavam propriedades no Estado Oriental, e foram estes que analisei.
} 
reconhecimento da posse e propriedade desses bens. Essa característica se torna especialmente importante ao avaliarmos que os bens não se encontram no território do Império e, portanto, respondem a outras leis. As informações constantes de um inventário têm um sentido de ordenação legal que as diferencia das listas de proprietários, fruto de uma tentativa de estatística estatal improvisada. Os dados dos inventários têm a força do reconhecimento do Estado sobre o patrimônio material dos indivíduos que tomam parte nos processos, enquanto a natureza das listas era política, ao reconhecerem um volume de patrimônios em território estrangeiro. Ambos são manifestações diferentes da presença do Estado imperial na fronteira meridional. Os contextos de produção desses diferentes documentos permitem o acesso a informações de pontos de vista distintos.

As listas do RRNE foram produzidas por comandantes de fronteira, a pedido do presidente da província, segundo informações coletadas entre contatos locais. Diferentes indivíduos compilaram os dados dos documentos apresentados; ao menos cinco oficiais enviaram listas, contendo no total, 1.353 propriedades listadas e 1.198 nomes de súditos do Império. Essa diversidade de relatores parece ser fonte de alguns problemas de sobreposições, duplicações e imprecisões em torno de dados e nomes.

Provavelmente, esses problemas também estivessem ligados ao alcance do conhecimento que esses homens tinham sobre os brasileiros no Estado Oriental. O período de produção das listas foi reduzido em relação ao tamanho da tarefa e as informações não foram colhidas a partir de uma verificação in loco, como num censo, ou padrón, ou listagem de fogos. De fato, se observarmos o caráter do método, poderíamos defini-lo pelo "rumor": as listas são fruto de informação indireta, manipulada sem condições práticas de verificabilidade. De qualquer forma, sua legitimidade não fica comprometida por sua imprecisão

O RRNE impresso apresentado pelo ministro e secretário de Estado Paulino Soares de Souza na terceira sessão da oitava legislatura da Assembleia Geral Legislativa, tinha no seu Anexo A, intitulado "Negócios do Rio da Prata", uma série de notas de discussão. Nas suas primeiras quarenta páginas e nas vinte finais, estão impressos documentos diplomáticos que dão conta da comunicação com a República Argentina, especialmente através do Ministro Thomaz Guido e com as autoridades 
uruguaias, incluindo Dom Manuel Oribe, sobre os procedimentos do Barão do Jacuí na República Oriental; todavia, tais dados não compõem o corpo principal das preocupações deste trabalho.

As relações de brasileiros que têm propriedades no Uruguai complementam essa discussão diplomática, como um adendo de comprovação, dado que uma das acusações realizada por Thomaz Guido era a de que as reclamações sobre as violências sofridas pelos brasileiros são vagas e sem precisão, não apresentando provas dos fatos que permitiriam a Oribe processar, julgar e condenar criminosos. As listas foram compiladas pelo presidente da província do Rio Grande do Sul, encontrando-se entre as páginas 41 e 73, divididas em dois envios ao Ministério dos $\mathrm{Ne}$ gócios do Estrangeiro.

As mais completas dessas listas, as que se referem às propriedades localizadas na região ao sul do Quaraí, produzidas pelo Comandante das Fronteiras do Quaraí e Missões, carregam informações importantes, como a localização dentro da região, indicada por limites naturais e pelos lindeiros e sua situação de posse; as listas que tratam das propriedades nas regiões da fronteira do Chuí e da fronteira de Jaguarão e Bagé e a de Tacuarembó trazem dados como a localização da propriedade e em posse de quem se encontrava; as demais, divididas por regiões, apresentam apenas o nome do proprietário e o tamanho da propriedade, às vezes declarando se estava embargada ou não e se estava em processo de partilha de herança. Muitas propriedades dessa lista têm o tamanho ignorado. Essas diferenças impedem que se observem os dados de forma homogênea e se possam estabelecer grandes comparações entre as propriedades. Ainda assim, essa configuração das listas merece algumas considerações.

\section{O espaço e sua divisão: uma percepção de projeto político}

As listas de 1850 foram produzidas usando limites que muitas vezes dividiam departamentos uruguaios em áreas menores do que estes tinham contemporaneamente. O curioso é que essas divisões coincidem em certa medida com a atual configuração departamental do norte do Uruguai $^{2}$, mostrando que a conexão dos homens com o espaço tem raízes

2 As regiões descritas na lista correspondem aos atuais departamentos: Rocha - Fron- 
em processos históricos, e, em parte por isso, optei por respeitar essa divisão ao apontar a distribuição dessas propriedades pelo Estado Oriental.

A própria divisão departamental uruguaia tem como importante componente o período de ocupação luso-brasileira durante a Cisplatina, especialmente quando pensamos nos territórios ao norte. Cerro Largo foi um dos três departamentos criados por Carlos Federico Lecor, o Barão de Laguna, chefe em armas e governante brasileiro na Cisplatina. A região, considerada desabitada por Artigas menos de uma década antes, foi largamente ocupada por brasileiros interessados pela criação de gado (Arocena, 2011, p. 55-56).

A participação direta de Dom Fructuoso Rivera no processo de conformação do departamento de Durazno esclarece como esse processo se deu durante o período da Cisplatina. Até 1822 o território entre os rios Yí e Negro fazia parte da jurisdição do departamento de San José. Parte das povoações que datavam do período em que portugueses e espanhóis disputavam o território da Colônia de Sacramento, San José era administrado por famílias há muito ali estabelecidas e que eram profundamente antipáticas à anexação ao território brasileiro. Rivera, que nesse período estava servindo ao Império do Brasil como comandante da campanha, envolveu-se pessoalmente na fundação da Vila de San Pedro de Durazno. A intenção de Dom Fructo era reduzir a jurisdição de San José e abrir um espaço político para seus aliados (Arocena, 2011, p. 57).

Durazno compôs uma nova frente de ocupação da campanha, ao sul. Alguns brasileiros que participavam das forças comandadas pelo General Lecor receberam de Rivera grandes extensões de terras nas proximidades do Rio Negro, em direção ao departamento de Cerro Largo. Outras grandes áreas foram concedidas a homens que acompanhavam as tropas do próprio Rivera, beneficiando o grupo que era conhecido como Club del Barón e que pode ser considerado o precursor do partido colorado (Rilla, 2004). A possibilidade de conceder terras, tão característica dos

teira do Chuí e São Miguel; Rivera - Fronteira do Jaguarão e ao norte do Rio Negro, Fronteira de Bagé; Tacuarembó - Tacuarembó; Artigas - Norte do Arapehy e ao Sul do Quaraí; Salto - Ao sul do Arapehy-Grande e ao norte da Coxilha do Haedo e Salto; Cerro Largo e Treinta y Tres - Cerro Largo; Durazno; Maldonado e Lavalleja - Maldonado; San Jose; Colonia; Montevideo e Canelones - Montevidéu; Paysandú - Paysandú e Rio Negro; Soriano - Soriano e Mercedes. 
comandantes militares portugueses, foi amplamente usada por Dom Fructo na construção de seu cabedal político e social enquanto serviu aos portugueses e depois aos brasileiros, para depois se voltar contra o próprio Império, quando da adesão ao grupo dos Treinta y três orientales.

No mesmo período do início da década de 1820 formaram-se os povoados de Rincón de Tía Ana - que depois se tornaria Tacuarembó - e Salto. Resultado do incremento da população indígena através da migração resultante das disputas entre o General Artigas e Francisco Ramírez, a ocupação do centro do Estado Oriental foi bastante tardia.A necessidade de incorporar esses povoados - especialmente Salto, tão próximo do território das Províncias Unidas - levou à criação de novos departamentos no Norte.

A criação de postos de autoridade política não respondia apenas à necessidade de firmar a posse dos portugueses e depois dos brasileiros sobre o território. As rivalidades políticas e a possibilidade de reivindicação do território pelas Províncias Unidas exigiam a criação de espaços para gratificação dos homens fiéis à Coroa. Avançar em direção do interior da Cisplatina era a forma como os luso-brasileiros pensavam garantir condições de prosperar. Mas no caso das duas povoações citadas, fixar homens confiáveis era um contrabalanço da sempre instável população indígena. Em muitos momentos, tribos nômades como os charruas, tornavam-se os piores inimigos dos pecuaristas, assaltando os rebanhos (Klein, 2007). Ocupar o território era também uma tentativa de ordenar a campanha, tanto mais que essa onda de migração indígena se encontrava com uma das mais importantes frentes de avanço da pecuária desde o Rio Grande do Sul, marcada pela criação de posições militares ao sul do Quaraí.

Quando finda a segunda campanha pela independência uruguaia, em 1828, o governo provisório de Lavalleja ratifica a existência de nove departamentos: Montevidéu, Maldonado, Soriano, Guadalupe (Canelones), San José, Colonia, Cerro Largo, Durazno e Paysandú. Ao fazê-lo, também afirma a presença estatal com maior força ao sul do rio Negro, dado que todo o norte era formado por duas dessas unidades administrativas. O Estado Oriental do Uruguai só iria se preocupar com a organização administrativa do território norte quase uma década depois, permitindo com essa postura que a região permanecesse com vínculos mais próximos com a província brasileira do Rio Grande do Sul e 
mesmo com a Argentina do que com a capital Montevidéu. De fato, é possível aventar que nos primeiros anos do Uruguai independente, muitos pontos do território eram mais bem conhecidos por autoridades brasileiras que tinham servido na Cisplatina do que pelas orientais.

As exceções a essa paralisia sobre o território ao norte do rio Negro foram a fundação de San Servando, a campanha de pacificação iniciada por Rivera em 1831 e a criação de San Fructuoso de Tacuarembó em 1832 (Michoelsson, 1990, p. 50). As tropas da campanha foram compostas pelos guarani-missioneiros que haviam migrado do território argentino e iniciado a colônia de Bella Unión no ponto mais extremo do noroeste do Estado Oriental (Favre, 1996, p. 323). A campanha visava diminuir a presença de bandos de desordeiros e ladrões de gado e principalmente fixar famílias no vasto território. Mas, de fato, essa campanha significou o extermínio dos grupos nômades de charruas que ainda subsistiam na campanha oriental, no episódio conhecido como a Matanza del Salsipuedes $^{3}$.

Os anos 1830 no Estado Oriental contaram ainda com outro movimento institucional que acabou por consolidar a propriedade da terra de muitos brasileiros, não sem antes estabelecer pontos de conflito. Um grande processo de regularização fundiária foi iniciado e basicamente seu ponto nefrálgico tratava da questão do reconhecimento ou não da propriedade das terras confiscadas e repassadas a aliados de Artigas durante o período revolucionário, além do reconhecimento da propriedade sobre uma miríade de posseiros. A questão era complexa, dado que estava marcada também por uma série de reclames realizados por proprietários coloniais ou brasileiros que haviam recebido as terras das coroas espanhola ou portuguesa e de fato nunca tinham conseguido ocupar essas terras, ou ao menos, não completamente. A questão ainda passava pelas terras públicas ocupadas por muitos indivíduos sem autorização, baseados no princípio de que, se o ocupante possuía gado na terra, tinha o direito de ocupá-la; por sua vez, muitos líderes orientais, entendiam que a compra, pelos posseiros, dessas terras públicas representaria a solução para as rendas estatais deficitárias.

3 Esse episódio marca a chacina ordenada pelo presidente Rivera da maioria das lideranças indígenas e de seus povos, numa emboscada armada quando estes estavam reunidos próximos ao Arroio Salsipuedes para reafirmar sua amizade com a autoridade presidencial uruguaia. 
Durante os dois primeiros anos da década de 1830, Rivera e Lavalleja usaram dessas disputas para fazer amigos e inimigos, favorecendo quando possível os aliados, imputando a culpa ao adversário sobre as perdas, enquanto os desalojamentos massivos e as exigências de aquisição da terra pública ocupada levaram a agitação à campanha. A prática da Cámara de Justicia era aplicar uma política de defesa irrestrita da propriedade colonial e brasileira, o que favorecia em muito os estancieiros na fronteira norte. Em 1832, a situação estava beirando a revolta, largamente incentivada por Lavalleja e seus partidários. O Estado começa uma política de intermediação entre os proprietários e os posseiros, fazendo com que os segundos comprassem as terras dos primeiros. Caso os proprietários não concordassem com o preço negociado, o Estado desapropriava as terras pagando valores largamente vantajosos aos proprietários e colocava as terras à venda para outros posseiros com melhores recursos. Esse processo implicou o desalojamento de um número considerável de posseiros, que passaram a se amontoar nas terras públicas ao redor dos povoados - protegidas desse processo - e garantiu a formação de propriedades maiores (Bertino; Millot, 1991, p.133-134).

A partir de 1834, com o país às voltas com mais uma disputa eleitoral que virtualmente poderia se transformar em revolta armada e com as dívidas públicas tornando impraticável sustentar a defesa do governo, estabelece-se a exigência da aquisição das terras públicas por parte de seus ocupantes, aumentando o efeito de concentração fundiária.

El proceso de reversión y enajenación y transacciones se hizo por intermedio de Comisarios y produjo el definitivo dislocamiento de las relaciones solidarias entre los poseedores, iniciadas por Lecor:los poseedores no escapaban a la ley de concentración. Todo dependía de la capacidad económica porque el campo se poseía con ganado y se defendía con peones, agregados y esclavos y de las relaciones que se pudiera tener con los caudillos o con el centro de poder montevideano. Al norte, los brasileños ocupaban la tierra de muchos donatarios y emigrados desaparecidos. [...] La política de Obes condenó al desalojo o sometió a la mayoría de los pequeños donatarios y poseedores. Consolidó a grandes e medianos poseedores sobre todo vinculados al grupo ministerial y a Rivera y em general a los que tenían recursos, con las mejores tierras. (Bertino; Millot, 1991, p. 136) 
Foi nesse período, que coincidiu com a eclosão da Revolução Farroupilha, que muitos brasileiros compraram grandes extensões de terra no Estado Oriental, especialmente nas regiões recentemente pacificadas na margem norte do rio Negro, dado confirmado pelas declarações em inventários, pela documentação diplomática e por anotações na versão manuscrita do RRNE. As terras eram baratas - segundo Barrán (1990), durante a Guerra Grande o preço da terra caiu a um terço de seu valor anterior, custando $\$ 0,60$ o hectare - e a produtividade da pecuária alta, provavelmente compensando a distância do mercado comprador.

Assim, a concentração de grandes propriedades de terras de brasileiros nos departamentos de Tacuarembó, Salto e Paysandú esteve diretamente ligada ao desalojamento dos posseiros pequenos e daqueles que não tinham recursos para manter grupos armados para defender suas terras, nem contavam com recursos políticos para acionar em Montevidéu. Os colorados financiaram sua manutenção no executivo oriental favorecendo a consolidação da ocupação do Norte pelos estancieiros rio-grandenses.

\section{Um espaço em três gerações: Cerro Largo e sua ocupação num período alongado}

O departamento de Cerro Largo, mais próximo ao litoral, teve uma conformação distinta, ou melhor, conformações distintas. Conformações porque o que correspondia ao departamento de Cerro Largo durante a Guerra Grande, ao menos no que toca às propriedades dos brasileiros, eram três regiões com diferenças de ocupação. As porções norte e leste, que é boa parte do atual departamento de Cerro Largo, tinham uma concentração de propriedades menores, ligadas a uma ocupação mais antiga, paralela àquela que ocupou os campos entre a lagoa Mirim e o oceano Atlântico. No centro e no oeste, onde hoje é a maior parte do departamento de Treinta y Tres, o tamanho das propriedades era maior. Essas duas áreas tinham alta concentração de brasileiros. Naporção mais ao sul, nas margens do rio Cebollati, que corresponde hoje ao norte de Lavalleja - que reuniu Minas e essa região - a ocupação era maior de nacionais, que descendiam de ocupantes do período do Vice-Reinado do Rio da Prata. 
A proporção da ocupação brasileira nessa última zona, no entanto, não deve ser subestimada. Como apontam Borucki, Chagas e Stalla, as cifras sobre a ocupação brasileira podem ser enganosas. Em Minas, em 1855 - já reunindo o sul do antigo departamento de Cerro Largo ao antigo departamento de mesmo nome -, os brasileiros consistiam em $7 \%$ da população, mas esses dados precisam ser observados de forma localizada geograficamente. Ao sul, os brasileiros não chegavam a $1 \% \mathrm{da}$ população; no centro, a 7,3\%; e no norte, a 17,3\% (Barrios Pintos, 2000). Contudo, esses não me parecem os dados mais expressivos, e sim os de que, no norte de Minas, os brasileiros constituíam-se em donos de 34\% das estâncias, de $42 \%$ do gado de rodeio e de $92 \%$ dos bovinos alçados (Borucki; Chagas; Stalla, 2004, p. 163).

As propriedades listadas em Cerro Largo - com este nome no rol do RRNE - contavam com a predominância da porção de menor tamanho de terras. Esse índice estava diretamente ligado ao fato de que as propriedades daquela região parecem ter sido atingidas com maior intensidade por processos de partilha sucessivas. Corroborando esse dado, o número de inventários que tratam de propriedades nessa região é maior, correspondendo a $84 \%$ do conjunto analisado.Ainda, 34,78\% dos inventários analisados tinham como forma de aquisição da propriedade declarada como sendo através de herança, e a esmagadora maioria se localizava em Cerro Largo. Correspondendo a uma ocupação mais antiga e, ao mesmo tempo, mais adensada, a região não apenas encontrou um índice de partilhas grande, como a dificuldade de realizar a reconcentração da propriedade nesses casos, e dificuldades para realizar a expansão das propriedades por simples ocupação de terras devolutas. Possivelmente o fato de ser uma região com proximidade do mercado consumidor do gado tenha influenciado nesse adensamento, não verificado nas áreas mais afastadas da fronteira, que exigiam maior investimento.

A maioria dos 483 proprietários estava estabelecida na porção mais a leste e ao norte do departamento de Cerro Largo. Essa área de ocupação antiga correspondia àquela que permitia acesso à lagoa Mirim, facilitando o escoamento da produção pelo porto de Rio Grande. Essa porção, assim como o atual departamento de Rocha, então a porção norte de Maldonado, e o norte de Minas, hoje Lavalleja, contrastavam com a ocupação de açorianos e descendentes de espanhóis do período do Vice-Reinado. Os descendentes dos colonos que fundaram as po- 
voações ao sul tinham seus negócios concentrados na agricultura e nas pequenas criações, enquanto o modelo expandido pelos lusitanos desde o norte era o da pecuária extensiva (Diaz de Guerra, 1988). Essas diferenças contribuíam significativamente para o estabelecimento de uma economia voltada para o mercado rio-grandense, ainda que tivesse produtores de menor porte que aqueles que se estabeleceram posteriormente no território em direção ao centro do Estado Oriental.

Essa presença tão pesada de brasileiros se refletia na dificuldade política e militar dos orientais em controlar a região: era através de Cerro Largo que Lavalleja acessava o Rio Grande do Sul no início dos anos 1830, buscando apoio em seus aliados brasileiros; da mesma forma que procedeu Rivera na década seguinte. Em 1831, Rivera ordena a fundação de San Servando, depois Vila Artigas e atual Rio Branco, como uma guarda de fronteira, numa tentativa de instituir um posto de aduana na região. Ao contrário de suas iniciativas na campanha da margem norte do rio Negro, San Servando foi erguida sob uma área densamente povoada, como uma presença estatal que buscava garantir a soberania do território. Lembrando da reclamação do alcaide daVila de Melo citada no início deste texto, a presença dos brasileiros na região era tão forte que praticamente excluía a existência de orientais em alguns partidos como eram chamados os distritos administrativos - da fronteira. A desconfiança num ponto onde a fronteira era tão indefinida era justificável.

Foi o governo blanco de Oribe, já avançada a Guerra Grande, que realmente intentou implementar uma política que timidamente apontaria para a orientalização do território ao norte do rio Negro.A ocupação por nacionais das regiões com maciça presença de brasileiros era imprescindível para a derrota dos colorados, tanto militar quanto politicamente. Nos dizer de Lucia Sala de Touron e Rosa Alonso Eloy, a campanha se blanqueó (Touron; Eloy, 1986). Os bens dos inimigos, muitas vezes brasileiros, foram vendidos e distribuídos para partidários do Gobierno del Cerrito. A divisão de Paysandú em três departamentos - Paysandú, Salto e Tacuarembó, em 1837, assim como a criação do departamento de Minas -, contando parte de Cerro Largo e Maldonado, as tentativas de diminuir a área das jurisdições do norte uruguaio e criar aparelhos administrativos que implicassem a presença direta de mais agentes do Estado, eram coerentes com a concepção de nação que os blancos defenderiam dali para frente. Essa concepção incluía a necessidade do monopólio do controle 
legal do território, diminuindo a influência que os brasileiros tinham sobre este (Arocena, 2011, p. 64).

\section{Orientalizar a República: um território ocupado por "estrangeiros".}

A afirmação generalizada por muitos historiadores (Souza, Prado, 2004), retirada de El Mensaje del Poder Executivo al Poder Legislativo, de que os brasileiros ocupariam com predominância 30\% do território oriental em 1857 (Bertino; Millot, 1991, p. 128) é de difícil comprovação, embora pareça ser corroborada por outras fontes contemporâneas (Zabiela, 2002, p. 23-25). Segundo o RRNE, em 1850, pertenceriam a brasileiros, apenas na fronteira do Chuí 342 léguas, e na de Bagé, 331 léguas, indicando de fato um acréscimo da presença brasileira. Se tomarmos a declaração de um deputado oriental em abril de 1862, que denunciava possuírem os brasileiros perto de quatro mil léguas, quase o equivalente à metade do território da República, o índice de 30\% para 1857 parece plausível, muito embora siga sendo uma suposição.A inexistência do tamanho de muitas propriedades no RRNE, além da apontada imprecisão e a divergência na forma do registro dos dados, não permite que se realize essa averiguação.

Apesar da inexistência de dados censitários confiáveis para os anos anteriores e imediatamente posteriores, que poderiam dar conta com precisão da presença de brasileiros no norte do território do país vizinho, esse parece ser um consenso largamente estabelecido pela historiografia de ambos os países. O primeiro censo estatístico geral realizado no Estado Oriental data do ano seguinte ao fim da Guerra Grande, em 1852. Muito embora os dados desse censo sejam bastante incompletos, não permitindo diferenciar brasileiros de outros estrangeiros, possibilitam algumas aproximações.

Observado o percentual de estrangeiros nos departamentos de Paysandú, Salto, Tacuarembó e Cerro Largo, que é o mesmo, 40,36\%, é possível supor que esse contingente fosse formado predominantemente por brasileiros. Excluindo Montevidéu, que por sua situação portuária e pelo caráter internacional de seu corpo de comerciantes possuía muitos imigrantes de nacionalidades diversas, os números dos demais departamentos, 
raramente chegando a ultrapassar $15 \%$, indicam que a presença dos brasileiros nos departamentos fronteiriços era responsável pelos altos índices de estrangeiros.

Tabela 1 - Censo geral uruguaio de 1852:habitantes nacionais e estrangeiros por departamento

\begin{tabular}{l|c|c|c|c|c}
\hline Departamento & Habitantes & Nacionais & Estrangeiros & $\begin{array}{c}\text { SEm } \\
\text { Classificação }\end{array}$ & $\begin{array}{c}\% \\
\text { Estrangeiros }\end{array}$ \\
\hline Montevidéu & 33.994 & 18.590 & 15.404 & - & 45,31 \\
\hline Canelones & 17.817 & 14.400 & 3.417 & - & 19,18 \\
\hline San José & 13.114 & 11.738 & 1.376 & - & 10,49 \\
\hline Colonia & 7.971 & 6.442 & 1.529 & - & 19,18 \\
\hline Durazno & 5.591 & 4.873 & 754 & - & 13,48 \\
\hline Maldonado & 9.733 & 8.421 & 1.312 & - & 13,48 \\
\hline Soriano & 9.031 & 7.757 & 1.274 & 6.462 & 14,10 \\
\hline Paysandú & 6.247 & 2.726 & 2.521 & 1.000 & 40,36 \\
\hline Salto & 7.364 & 4.392 & 2.972 & - & 40,36 \\
\hline Tacuarembó & 6.567 & 3.917 & 2.650 & - & 40,36 \\
\hline Cerro Largo & 6.541 & 3.847 & 2.604 & - & 40,36 \\
\hline Minas & 8.089 & 6.998 & 1.091 & - & 13,48 \\
\hline Total & 13.1969 & 9.4085 & 36.884 & 6.462 & 27,90 \\
\hline
\end{tabular}

Fonte: adaptado de Bertino e Millot (1991, p. 130).

Se tomarmos como fidedigno o depoimento de Dom Diego Lamas, comandante-geral em Salto em 1848, de que estava cercado de estancieiros brasileiros e com eles não podia contar (Magariños de Mello, 1948 , p. 342), ou o do ministro do Exterior oriental em 1852, que afirma que em Tacuarembó os brasileiros eram em maior número que os nacionais, podemos estimar que os números de estrangeiros nesses departamentos, assim como outros do norte, como Cerro Largo, Paysandú (Winn, 1997, p. 68-69) e mesmo em parte de Maldonado, correspondessem majoritariamente a brasileiros. Segundo Magdalena Bertino e Júlio Millot (1991, p. 128), a partir de 1851 a presença de brasileiros nos departamentos de fronteira se acentua. No censo de 1860, onde estão faltando os dados de Paysandú e Maldonado, os brasileiros seriam 19.106, estimando-se conservadoramente que chegassem a 21.700 
com os que viviam nos dois departamentos, o que por baixo resultaria em $10 \%$ da população nacional. Não eram os 40 mil brasileiros declarados pelo general Antônio de Souza Netto (Barrán; Nahum, 1967) três anos depois, ao argumentar pela intervenção militar brasileira a favor de Venâncio Flores, mas ainda assim, mostrava-se um número impactante, especialmente se observada a concentração dessa população brasileira na faixa da fronteira norte.

O problema da desproporção entre o número de orientais e de brasileiros era antigo. Na década de 1830 não era incomum encontrar brasileiros exercendo funções administrativas e de justiça no Estado Oriental (Zabiela, 2002, p. 26). Analisando o censo de 1852, segundo Bertino e Millot (1991, p. 130), observa-se que em algumas seções judiciais dos atuais departamentos de Artigas e Rivera os brasileiros representavam o dobro, às vezes o triplo, dos habitantes orientais. Na região entre os rios Arapehy e Quaraí, todas as propriedades pertenciam a brasileiros. Mais uma vez, o governo oriental respondeu à questão criando novas municipalidades, buscando estender a presença estatal e garantir o controle do território. Criam-se Cuareim (posteriormente renomeada como Artigas), Treinta y Tres, Santa Rosa del Cuareim, Arredondo e Rio Branco, todas próximas da fronteira. Esse movimento se mostra bastante condizente com aquele da fixação da propriedade da terra.

Até o fim da Guerra Grande, a posse e mesmo a propriedade da terra no Estado Oriental não eram completamente seguras. Como apontei anteriormente, o processo de regularização fundiária iniciado nos anos 1830 desacomodou um número grande de pequenos posseiros e de proprietários menores que não tinham título válido. Essa pode ter sido a motivação para muitos brasileiros inventariarem em comarcas do Império seus bens existentes no Estado Oriental. Como aponta Joseph Younger, ao pesquisar disputas judiciais no espaço platino, buscar a legitimidade de tribunais e cartórios em um ou outro país foi procedimento bastante utilizado para garantir a propriedade (Younger, 2008). Tanto pela insegurança reinante em períodos de conflito, quanto em momentos de paz, esse expediente podia ser empregado.

A viúva Eugênia Chagas de Oliveira foi um dos inventariantes que fez solicitação nesse sentido. Seu falecido marido possuía uma estância de 3 3/4 de sorte de estância no Cerro de Carpintería, no então departamento de Tacuarembó, a pouquíssima distância de Aceguá, um campo 
em Acharate, em Cerro Largo, além de um campo em Piratini. Ao abrir o inventário, em 1859, em Bagé, a viúva solicitou que os bens no Estado Oriental fossem levantados pelas autoridades locais, mas que "por ser de justiça", o juiz autorizasse que a partilha fosse realizada no Brasil. O juiz autoriza desde que as autoridades orientais permitam. O pedido foi enviado à Junta de Carpintería, que se pronuncia aceitando a situação desde que a viúva pague todas as taxas pela transmissão da terra, respondendo por si e por seus filhos menores. Depois de dois anos, Eugênia Chagas de Oliveira consegue fazer a partilha no Brasil. Ainda que tenha respeitado os trâmites burocráticos, a desconfiança da viúva em relação à justiça oriental fica clara, demonstrando que não considerava que a partilha naquele país tivesse o mesmo reconhecimento que se realizada no Império.

No início dos anos 1850 e mais ainda nos anos anteriores, nas décadas de 1840 e 1830, os inventários trarão bens partilhados no Brasil sem nenhum registro de comunicação com as autoridades orientais. Muitas vezes, o expediente remeterá realmente à total desconsideração da soberania do Estado Oriental (Benton, 2001). No caso das terras, essa postura pode estar bastante ligada à certeza de que a posse era a melhor garantia da propriedade, expediente que acompanhou a expansão lusitana na região. De toda forma, é possível observar que os herdeiros não costumam ignorar a existência de uma mudança de legislação e instituições, eles buscam manejar essas diferenças a seu favor, observando possibilidades nas brechas. Em todos os inventários verificou-se que os herdeiros recebiam sempre uma quantidade equivalente de bens no Brasil e no Uruguai, não acontecendo nenhum caso em que as heranças ficassem localizadas exclusivamente em um outro país. De certa forma, os envolvidos reconheciam que existia uma diferença entre os bens possuídos de um lado a outro da fronteira.

Uma possibilidade pelo uso desse artificio era a de garantir o reconhecimento de bens em um país, diante da impossibilidade de reconhecimento no outro, semelhante aos casos analisados por Joseph Younger e Lauren Benton. Esse é o caso do legado de Flora Gertrudes Maciel de Faria. Flora era tia-avó de Eliseu Antunes Maciel - pai do futuro Barão de São Luís - e do tenente-coronel Aníbal Antunes Maciel - pai do futuro Barão de Três Cerros, dois de seus herdeiros. Tendo falecido em novembro de 1852 e com inventário aberto no ano seguinte, Flora possuía, entre 
outros bens, uma estância em Tacuarembó, nas proximidades do Arroio Hospital que contava com nada menos que 19 léguas.

Contudo, o dado mais interessante na partilha dos seus bens não se encontra na divisão das terras e ou do gado. Na propriedade do Hospital viviam dois escravos, um de nome Serafim, de 36 anos, e outro chamado Manoel, de 48 anos, ambos crioulos e campeiros. Esses dois escravos, que pelas leis orientais seriam livres, foram partilhados. Manoel foi dado por conta da legítima de Eliseu Antunes Maciel e permaneceu em sua propriedade em Paysandú, em escravidão ilegal, provavelmente considerada legítima por ser avalizada por um processo estabelecido no Império. Esse não foi um caso isolado: nos inventários analisados foram encontradas dezesseis ocorrências nos anos entre 1848 e 1862, de escravos vivendo em propriedades no Estado Oriental e sendo partilhados em inventários no Império, ou seja, todas claramente transgredindo a abolição da escravidão no Estado Oriental.

Ainda assim, terras são o bem mais inventariado. Apenas sete inventários não apresentavam nenhum tipo de propriedade fundiária. Três desses inventários apresentavam propriedades de casas em áreas urbanas e quatro eram casos de arrendatários que declaravam rebanhos. Nos demais inventários, propriedade de campos e estâncias predominam, indicando em parte o movimento do crescente mercado de terras e as preocupações em assegurar sua propriedade em todos os meios legais possíveis, num contexto de valorização. No fim dos anos 1850, num momento de suspensão de conflitos, da quase inexistência de terras públicas com bons pastos para ocupar e um novo impulso com os investimentos de estrangeiros, especialmente ingleses, na criação de ovinos, o mercado de terras se encontrava bastante aquecido. $\mathrm{O}$ valor da terra havia passado da média de $\$ 0,6$ em 1852-1856 a \$2,09 em 1857-1861 (Barrán; Nahum, 1967, p. 29), num momento em que a suspensão das denúncias fixava a posse como propriedade.

Ainda que os maiores aumentos se concentrassem nas áreas de comportamento menos arcaico, onde estrangeiros compravam terras para a criação de ovinos (Bertino; Millot, 1991,p. 147), essa fixidez da propriedade, acompanhada da valorização da terra, levou a um processo que definitivamente garantiu aos brasileiros no norte não apenas segurança em relação à propriedade, mas a manutenção da concentração fundiária e seu gradativo aumento. Ao analisar algumas trajetórias, posteriormente 
pretendo exemplificar melhor essa relação, entendendo o que Bertino e Millot (1991) chamaram de comportamento arcaico. Por enquanto, basta apontar que essa concentração fundiária aumentava o poder dos estancieiros brasileiros, na medida em que implicava estabelecimentos cada vez maiores e num número proporcionalmente maior de agregados e peões empregados que dependiam deles para obter seu sustento - seja através de seu próprio trabalho, seja pela permissão para criar gado em terras desses grandes proprietários -, dada a diminuição drástica da possibilidade de acessar a terra por meio da posse ou da compra.

Parece importante verificar semelhanças nesse movimento de aumento do valor das terras no outro lado da fronteira, especialmente se considerado que o período coincide com a aplicação da Lei de Terras no Brasil. Datada de 1850 e regulamentada em 1854, a lei instituiu a aquisição através da compra como única forma legal de acessar a posse da terra no Império, não teve uma aplicação uniforme e muito menos imediata em todos os pontos do Império. No que compete à fronteira meridional, alguns estudos fornecem informações que se assemelham muito aos que observamos em relação às propriedades de brasileiros e à questão fundiária em geral no Estado Oriental (Garcia, 2005).

Outro fator importante estava localizado no Tratado de Limites assinado em 1852, que definiria a linha divisória da fronteira. O reconhecimento do território entre os rios Quaraí e Arapehy como território oriental, ao mesmo tempo que o Império detinha a integridade das águas da lagoa Mirim e do rio Jaguarão, levou a uma definição dos parâmetros legais sobre a ocupação, posse e propriedade das terras dessas áreas. Muito embora os efeitos dessas transformações possam ser observados ao longo da segunda metade do século XIX, os sinais da chegada dessas mudanças estavam presentes nas décadas anteriores e seus contemporâneos ofereceram resistência a essas mudanças.

Do total das propriedades, quase metade, $47,1 \%$, estava localizada ao norte do rio Negro. Se somada a proporção de estabelecimentos em Cerro Largo, 35,6\% das propriedades, podemos afirmar que essa distribuição aponta para a concentração das propriedades de súditos imperiais no norte e no litoral atlântico, com um total de $82,7 \%$ dos proprietários listados.

Esses dados, sem sombra de dúvida, demonstram que as grandes concessões de terras no primeiro quartel do século XIX, realizadas junto da 
expansão militar luso-brasileira, acabaram por permitir a fixação de um modelo de propriedade no norte oriental, o do latifúndio que, como apontado anteriormente, parece ter sido aprofundado pela política dos governos orientais nos anos 1830 .

\section{O mercado como regente da propriedade: gado e escravos}

$\mathrm{Na}$ virada da década de 1840 para a de 1850, alguns dos indícios das dificuldades causadas pela diminuição das possibilidades de compra já podiam ser localizados no RRNE.É importante atentar ao dado de que esta era uma lista de criadores de gado com estabelecimentos no Estado Oriental e não necessariamente de proprietários de estâncias. Nem todas as propriedades declaradas são dos cidadãos brasileiros que as ocupam. Existiam arrendatários, inclusive de grandes propriedades, como o caso da estância do Tacumbú, arrendada ao Barão do Jacuí pelo coronel Olivério José Ortiz, que contava com 18 léguas de extensão, além de outros possuidores.

Entre agregados, arrendatários e posseiros que se declaram em terras pertencentes ao Estado Oriental, temos 117 indivíduos declarados, totalizando $8,64 \%$ do total, um índice bem abaixo do verificado no Rio Grande do Sul do mesmo período. Esses cidadãos foram listados como possuidores de propriedades no país vizinho, mas deixava-se claro que esta propriedade não era a das terras que ocupavam, mas do gado. Se retirarmos os indivíduos que se declaram agregados e, portanto, provavelmente mantinham suas propriedades - possivelmente pequena quantidade de gado - nas terras dos seus patrões, restam-nos 76 cidadãos que se declararam arrendatários privados ou ocupando campos de propriedade pública, alguns deles pagando taxas - e, portanto, em virtual condição de se tornarem proprietários -, o que leva ao percentual significativo de 5,61\%.

É importante questionar o que faria com que esses cidadãos fossem incluídos nessa lista, formulada para, antes de tudo, enumerar os prejuízos de brasileiros no Estado Oriental, geralmente ligados à tomada de propriedades. Creio ser esse um indício de que os maiores prejuízos não fossem aqueles sofridos pelos brasileiros que viviam no Estado Oriental, mas os 
que a interrupção das atividades desses produtores causava aos que participavam do circuito comercial em que ela estava inserida. Essa percepção me parece claramente reforçada pelo número de propriedades listadas que não se encontravam em poder do proprietário, que totalizam 190.

A grande maioria dessas propriedades, 186, encontra-se nas listas com dados mais completos e ficava localizada nas fronteiras do Chuí, de Jaguarão, em Tacuarembó e na região do rio Arapehy. Graças aos dados mais completos de algumas delas pode-se compreender melhor o impacto que a Guerra Grande vinha causando na produção pecuária desses estancieiros. Dos 190 estabelecimentos nessa condição, apenas 47\% foram listados como simplesmente embargados. Os demais estabelecimentos tinham sido abandonados em algum momento pelos proprietários, alguns sofrendo embargo posterior, outros quedando apenas sem quem os administrassem.

As condições que implicavam o abandono das estâncias eram determinadas, grosso modo, pela impossibilidade de que cumprissem suas atividades produtivas. O caso dos dois filhos de Olivério José Ortiz, Olivério Filho e Gaspar, que criavam gado como agregados na estância do Tacumbú, pode ser muito esclarecedor. Em 1848, o Barão do Jacuí arrendou a propriedade com todos os gados de seu proprietário. Essa situação está descrita no RRNE, logo acima da descrição das propriedades dos filhos de Olivério. Possivelmente os gados dos filhos fossem vendidos conjuntamente com o do pai, separando-se apenas o valor correspondente, prática bastante comum. A necessidade de listar Olivério Filho e Gaspar residia no fato de que a impossibilidade de tirar seus gados do campo embargado prejudicava a condução de seus negócios. Não apenas por lhes causar prejuízo imediato, com o gado perdido -essa também era uma grande preocupação, dado que a quantidade de gado alegada pelo Barão na Tacumbú chegava à cifra expressiva de 40 mil cabeças. O prejuízo dos irmãos Ortiz, caso a situação se prolongasse, residiria na incapacidade de manter seus compradores.

A possibilidade de que a escassez de matéria prima desarticulasse o mercado de gado era real. Muitos charqueadores de Pelotas se viam em sérias dificuldades depois de uma sequência de duas décadas ruinosas (Vargas, 2013), marcadas pela derrota da Cisplatina, a eclosão da Revolução Farroupilha e a continuidade da Guerra Grande no Estado Oriental (Bell, 1998). 
A propriedade de Olivério José Ortiz se encontrava numa das listas com maior detalhamento, aquelas que tratavam das regiões ao sul e ao norte do rio Arapehy e que tiveram listas com detalhes que incluíam nomes de capatazes e agregados. Essa era uma das porções do território uruguaio reivindicadas como brasileira pelos sul-rio-grandenses, inclusive porque a totalidade das terras privadas lhes pertencia. Além disso, essa foi uma das regiões particularmente envolvidas no episódio das califórnias e, portanto, alvo tanto das investidas dos grupos armados brasileiros quanto das tropas do comandante blanco Dom Diego Eugênio Lamas. A necessidade dessa lista ser particularmente detalhada se encontrava no fato político de que era uma região em disputa, ao menos na perspectiva dos estancieiros daquela fronteira.

O conteúdo de algumas das listas parece ter sofrido influência de outros documentos. A presença de refugiados da Guerra Grande em terras pertencentes ao Estado imperial - os chamados "Rincões Nacionais", denominação comum em vários pontos da fronteira para as terras da União reservadas para o cuidado dos cavalos das tropas militares - foi um dado que se reproduziu em quase todos os municípios sul-rio-grandenses do limite com o Estado Oriental, situação confirmada pelas listas existentes nas correspondências das câmaras municipais ao presidente da província.

A lista de refugiados de Jaguarão foi produzida no final da década de 1840 e trazia não apenas os nomes dos chefes de família como os números de filhos, agregados, escravos, animais e, principalmente, de que viviam. Todos os proprietários brasileiros ali listados - e não todos arrolados, dado que existiam refugiados orientais - aparecem nas diferentes listagens de 1850 e curiosamente mesmo nas listas com poucas informações, a grande maioria das propriedades desses refugiados aparece com a informação do embargo pelas tropas blancas ou do abandono causado pela violência.

O casal Comba Barbosa de Alencastro e Jerônimo Batista Alencastro, inventariados em 1852, eram parte desses refugiados instalados no rincão nacional de Jaguarão, dos quais temos muitos dados. No processo, além da propriedade de Catallán, que no RRNE aparece embargada pelo comandante blanco Dom Diego Lamas, constam ainda 45 escravos e a chácara de Jaguarão. A propriedade de Catallán tinha sido abandonada pela viúva após o assassinato de Jerônimo Batista Alencastro, num caso 
que permanece pouco esclarecido na documentação. De toda forma, a inexistência de outras propriedades - a chácara do rincão nacional foi uma concessão para refugiados, portanto acessada depois do abandono de Catallán -, que não a estância no Estado Oriental, indica que os 45 escravos do casal estivessem naquele estabelecimento. As notícias sobre o recrutamento forçado de escravos de brasileiros e as reclamações diplomáticas que indicam que o assassinato de Alencastro teve o envolvimento de autoridades orientais, podem apontar que a vítima demonstrou resistência ao recrutamento de seus cativos.

A presença de um número tão expressivo de escravos implica a percepção sobre como os brasileiros estabelecidos no Estado Oriental administravam suas estâncias. O caso dos Alencastro exige algumas considerações necessárias. A primeira delas se refere àquilo que estudos mais recentes têm afirmado (Osório, 2007), o reconhecimento do trabalho escravo nas estâncias como importante para a lida com o gado e não apenas em atividades secundárias, como supunham trabalhos mais antigos.

Quando a viúva Comba Alencastro foi arrolada como refugiada em Jaguarão, em 1848, ocupava uma chácara de 10 quadros com benfeitorias junto a um de seus filhos e 25 escravos, dizendo que vivia da agricultura. Creio que a diferença no número apresentado no inventário quatro anos depois se deva possivelmente a uma distribuição dos demais cativos entre os herdeiros que não acompanhavam a mãe naquele estabelecimento. Esse expediente, em que os herdeiros mantinham em seu poder bens que pertenciam aos pais, como em empréstimo, funcionava como um adiantamento de herança, bastante comum naquele contexto (Farinatti, 2010).

Ao se retirar do Estado Oriental com esse número de escravos, Comba protegeu seu patrimônio mais valioso: escravos podiam ser vendidos facilmente ou alugados, especialmente se fossem trabalhadores especializados. Ainda, permitiu que seus filhos tivessem formas de acessar facilmente esse patrimônio, permitindo assim que ele fosse capitalizável. A terra, esse era o bem mais instável e, ao mesmo tempo, indisponível como capital, mesmo que fosse uma propriedade de médio porte como aquela de Catallán. Infelizmente, como o inventário não foi concluído, não foi possível avaliar qual o percentual que esses escravos representavam sobre o montante dos bens, mas tendo a concordar com a historiografia que aponta que, nesse período, a escravaria podia compor a maior porção do patrimônio (Bell, 1998). 


\section{Fronteira política e fronteira agrária: dois territórios distintos}

Outro ponto a considerar sobre as propriedades de produção pecuária - e aqui excluo propositalmente as propriedades de charqueadas abandonadas nas proximidades de Montevidéu - que sofreram embargo ou foram abandonadas se refere à sua localização. Essas propriedades se encontram nas áreas de maior concentração de brasileiros. Nenhuma propriedade das listagens dos departamentos mais ao sul constava como fora do poder de seu dono. Esse me parece um indicativo importante de que as ações dos blancos objetivavam um confronto com os brasileiros de forma sistemática nas regiões em que eles eram maioria.Tratava-se de estabelecer o monopólio da ordem e da legalidade, não permitindo a existência de outro entendimento que não o do projeto de Estado Oriental defendido pelos partidários de Oribe.

O topo deste grupo com propriedades embargadas indiscutivelmente está entre aqueles proprietários que tem mais de 20 léguas de terras. Nas listas existem 44 propriedades com estas dimensões, pertencentes a 42 proprietários. Se acrescentarmos a estes os proprietários que, tendo mais de uma propriedade, somavam essa extensão de terras, o número sobe para 46 proprietários. Dentre esses, ao menos 11 proprietários, ou seja, $24 \%$, declararam que suas terras haviam sido tomadas pelos blancos, quase um quarto dos maiores proprietários com terras no Estado Oriental do Uruguai. Se considerarmos que o índice geral de embargos fica em $14 \%$, podemos considerar que esse grupo foi atingido de forma mais contundente. Os embargos, contudo, concentram-se no norte, enquanto os abandonos têm maior expressão no sul, região com menor presença de brasileiros.

De toda forma, a presença menor dos brasileiros ao sul indica também que os investimentos dos grandes líderes orientais se direcionavam para aquele espaço. Concordo com Bertino e Millot (1991, p. 125)quando afirmam que o acesso à terra esteve ligado às relações mantidas com o centro de poder em Montevidéu, mas acredito que essa condição estava combinada a outra. Nas áreas com maior concentração de brasileiros, suas práticas orientavam o mercado para uma racionalidade distinta, aquilo que Bertino e Millot denominaram rapidamente de um "comportamento arcaico". As grandes disputas estabelecidas entre as autoridades 
blancas e os brasileiros a partir da Guerra Grande são produto do encontro de duas fronteiras agrárias em fechamento: a que era empurrada desde o sul pelos grandes estancieiros orientais e as diferentes frentes empurradas pelos brasileiros desde a fronteira norte. A escassez de terras para serem distribuídas implicava uma alteração do jogo político, levando a uma reorientação do próprio projeto político, o que, no caso dos blancos, refletia-se em embargos e confiscos.

Mesmo que não disponhamos de dados para caracterizar o mercado de terras nas áreas ocupadas por brasileiros - especialmente porque cobrir todo esse território exigiria uma pesquisa de muito maior fôlego -, algumas considerações são cabíveis. Em pesquisa anterior me deparei com dados sobre a venda de propriedades de criação de gado no Estado Oriental realizadas por charqueadores brasileiros (Menegat, 2009). Naquele momento, minha atenção estava concentrada em entender as redes sociais que permitiram que um sujeito proveniente da distante província de Minas Gerais se estabelecesse como charqueador e se tornasse um dos principais líderes da Revolução Farroupilha. Para isso, percorri todos os laços que aquele indivíduo criou; especialmente, persegui a rede familiar de sua esposa, oriunda de uma grande família, com pai e tios charqueadores e outros tios e primos criadores de gado.

Os Rodrigues Barcellos eram uma família de descendentes de açorianos que migraram para Rio Grande logo antes da tomada dessa vila pelo governador espanhol do Rio da Prata, Pedro Cevallos, em 1863. A fuga de Rio Grande levou a família a se instalar nos campos deViamão, até a retomada daquela vila, quando gradualmente os filhos de Antonio Rodrigues Barcellos e Rosa Perpétua de Lima voltaram seus investimentos para o sul, alguns se estabelecendo nas proximidades de Rio Grande, onde se fundaria alguns anos depois a Vila de São Francisco de Paula, a futura Pelotas, outros se dirigindo para a campanha, alguns conseguindo fazer ambos.

José Rodrigues Barcellos, que se tornaria uma das maiores fortunas entre os charqueadores da primeira geração, serviu no comando da fronteira de Jaguarão até chegar ao posto de major, nos anos da conquista da Cisplatina. Depois, fixou-se em Pelotas, onde possuiu um estabelecimento de charqueada e atuou no comércio atlântico. Naqueles anos, fora descrito como um "dos maiores proprietários da fronteira do Rio Grande" e de boa conduta quando no comando dos oficiais militares (Vargas, 
2013, p. 458). Seu irmão, Luiz Rodrigues Barcellos, possuía uma grande propriedade em Bagé e outra na porção norte de Cerro Largo, com 10 léguas. Outro irmão, Bernardino, da mesma forma possuía uma propriedade, da qual se ignorava a dimensão, no mesmo departamento. Essa propriedade era administrada por um dos filhos de Bernardino, Joaquim, que desde essa propriedade comprava gado de diferentes produtores não apenas para alimentar a charqueada do pai, mas também para o do cunhado, Domingos José de Almeida.

Os laços entre os irmãos eram fortes, como diferentes documentos atestam. No inventário de Dona Ana Bernarda da Cunha, esposa de José Rodrigues Barcellos, o principal credor era outro irmão, Cipriano Rodrigues Barcellos. Cipriano foi descrito pelo visitador Dom José da Silva Coutinho, em 1815, como um dos mais ricos da então pequena freguesia de São Francisco de Paula. Assim como José, Cipriano foi um dos mais ricos charqueadores da primeira geração em Pelotas. Tão rico, que estabeleceu seus negócios também no Estado Oriental, primeiro com uma propriedade de criação na Costa do Jaguarão e depois com uma charqueada em Maldonado. Mas sua riqueza não permaneceu investida nessas propriedades. Nos últimos anos de vida, Cipriano se tornou um capitalista, vivendo principalmente de rendas.

No ano de 1845, o Comendador Cipriano Rodrigues Barcellos e sua esposa Rita Bernarda da Silva compareceram ao $2^{\circ}$ Tabelionato de Notas para vender a estância situada na margem uruguaia do Jaguarão. Os compradores eram os irmãos Joaquim e Florêncio Correa Mirapalheta. Assim como o comendador e seus irmãos, os Correa Mirapalheta descendiam de famílias açorianas que se instalaram em Rio Grande ainda no século XVIII. Assim como os Rodrigues Barcellos, eles haviam estendido suas atividades econômicas além da fronteira nas primeiras décadas do século XIX.Além disso, membros de ambas as famílias tinham contraído matrimônio nas décadas anteriores. Cipriano vendia sua propriedade para velhos conhecidos.

Caso semelhante se deu com a compra de um campo no Estado Oriental pelos filhos de José Pedro Rodrigues, no ao de 1857. O campo foi vendido pelo comendador Domingos Faustino Correa a uma sociedade formada por netos do comendador José Rodrigues Barcellos. Para entender sua relação com os Rodrigues Barcellos, tenho de remeter ao fato de que ele participava, de forma bastante pronunciada, de uma rede fa- 
miliar que concentrava boa parte dos negócios na porção norte do então departamento de Maldonado, hoje Rocha. Nas décadas anteriores a esse negócio, especialmente nos anos 1830, o grande centro das compras de gado dos irmãos Barcellos parece ter se localizado nessa região. Ali também Cipriano teria participado do comércio ilegal de escravos, nos anos 1830, bem como montado uma charqueada durante a Revolução Farroupilha (Monquelat, 2010, p. 151).

Apesar de tímidos, esses são indícios de que esse mercado estava orientado para venda dentro de um círculo de relações, excluindo especialmente a comercialização da terra com orientais. Em realidade, todos os inventários que têm indicação da compra de campos no Estado Oriental - não são muitos, sete no total - indicam que a venda foi realizada por brasileiros, bem como os arrendamentos indicados nos processos. Outros oito inventários indicam que terras do inventariado estavam arrendadas por outros brasileiros. Se for possível supor que havia uma similaridade no funcionamento do mercado de gado com o do mercado de terras, a possibilidade de que este fosse bastante refratário a negócios com orientais aumenta.

O mercado de gado tem uma dinâmica mais fácil de rastrear nos inventários, por meio das contas correntes e das dívidas ativas e passivas. $61,9 \%$ dos inventários apresentam alguma indicação sobre a venda ou compra de gado. A grande maioria dos inventariados tinha dinheiro a receber pela venda de uma ou duas safras anteriores e nos permite verificar dois padrões de venda. O primeiro era constituído por um comerciante que comprava o gado. Esse padrão era mais comum nas áreas mais próximas da fronteira, onde o acesso às casas de comércio me pareceu ser regular. Em algumas situações, os criadores eram devedores desses comerciantes, indicando que nem sempre o gado necessariamente era pago em dinheiro, mas entrava numa conta corrente. Assim, fora da safra os estancieiros se abasteciam dos gêneros necessários no comércio e o acerto de contas era realizado na safra. Esse modelo foi particularmente empregado por criadores menores, ou ao menos pelos que tinham quantias menores para receber nos inventários, e não estava ligado apenas ao abastecimento das charqueadas brasileiras, mas ao consumo de gado da população em geral.

Outra forma de organizar o comércio de gado era aquela em que um estancieiro intermediava a venda de outros criadores. Nessa modalidade, 
as tropas eram formadas na safra e enviadas ao destino por um pecuarista que vivia no Estado Oriental, ou administrando terras de outrem ou que tinha bons contatos nos mercados consumidores. O inventário de João Simões Lopes, aberto em 1853, traz indícios interessantes de como esse mercado se organizava. O pai do futuro Visconde da Graça era um charqueador de grandes proporções (Vargas, 2013, p. 313), engajado no comércio atlântico (Berute, 2011, p. 91-92) e criador com grandes propriedades no Brasil e no Estado Oriental. Em seu inventário suas dívidas passivas foram classificadas entre "recebíveis, dificeis de receber e dadas como perdidas", um indicativo do volume movimentado em sua atividade mercantil. Porém, nas dívidas ativas, muitos valores eram destinados a nomes que identifiquei no RRNE, com propriedades numa região acessível desde as propriedades de Simões Lopes.

Ao inventariar os bens que possuía com suas duas esposas falecidas, Maria Faustina Furtado e Cipriana Gonçalves, o major Diogo Félix Feijó indicava uma série de dívidas do segundo casal com Rafael de Souza Netto. Sobrinho do general Antônio de Souza Netto, um dos líderes farroupilhas, Rafael era casado com Bárbara Leonor Gonçalves da Silva, sobrinha de Bento Gonçalves - o principal líder dos farrapos - e era proprietário de uma grande estância próxima a Bagé. Aliás, entre os vizinhos de Rafael estavam parentes de outros líderes farroupilhas, como outros Gonçalves da Silva e Silveira Brum, e também de muitos charqueadores, como os Azevedo e Souza e os Rodrigues Barcellos, além do dito major Feijó e seus filhos. Rafael de Souza Netto, assim como seu tio mais ao sul, provavelmente arregimentava tropas de gado, comprando de seus vizinhos, que eram levadas às charqueadas de Pelotas.

A dívida do segundo casal possivelmente era resultado de algum adiantamento por tropas que não puderam ser entregues nos anos finais da Revolução Farroupilha, indicando que as relações que mediavam as compras eram ditadas também pela perspectiva de contar com o suporte do comprador em momentos difíceis, numa rede de crédito que amarrava o criador àqueles que mediavam a comercialização das tropas (Bell,1998). O mercado de gado parecia ser guiado por outras normas que não apenas a da oferta e procura. Jonas Vargas (2013, p. 299), ao analisar o grupo de charqueadores de Pelotas, encontrou outros exemplos dessa prática.

Compreender que a lógica desse mercado era marcada pelas boas conexões com os mercados consumidores e pelas relações de confiança 
estabelecidas e alimentadas ao longo dos anos não exclui o fato de que eram os proprietários maiores que organizavam esse padrão de comércio de gado na campanha. Entender os tamanhos das propriedades e o impacto que isso tinha sobre a produção pode ser esclarecedor. Do total de 1.353 propriedades listadas no RRNE, 974 apresentavam dimensões registradas, distribuídas segundo a Tabela 2. Como se pode perceber, o maior número de propriedades ficava na faixa de menor dimensão, o que não quer dizer que fossem pequenas propriedades.

Tabela 2 - Número de propriedades segundo as listas do RRNE

\begin{tabular}{l|c|c}
\hline \multicolumn{1}{c|}{ REgiño } & $\begin{array}{c}\text { NúmERO DE } \\
\text { PROPRIEDADES }\end{array}$ & PERCENTUAL \\
\hline Fronteira do Chuí e São Miguel & 36 & $2,6 \%$ \\
\hline $\begin{array}{l}\text { Fronteira do Jaguarão e ao norte do rio } \\
\text { Negro, fronteira de Bagé }\end{array}$ & 154 & $11,3 \%$ \\
\hline Tacuarembó & 161 & $6,4 \%$ \\
\hline Norte do Arapehy e ao sul de Quaraí & 78 & $5,7 \%$ \\
\hline $\begin{array}{l}\text { Ao Sul do Arapehy e ao norte da coxilha } \\
\text { do Haedo }\end{array}$ & 483 & $35,6 \%$ \\
\hline Cerro Largo & 33 & $2,4 \%$ \\
\hline Durazno & 39 & $2,8 \%$ \\
\hline Maldonado & 15 & $5,8 \%$ \\
\hline San José & 8 & $1,1 \%$ \\
\hline Colonia & 124 & $0,5 \%$ \\
\hline Montevidéu & 39 & $9,1 \%$ \\
\hline Salto & 17 & $2,8 \%$ \\
\hline Paysandú & 1.353 & $1,2 \%$ \\
\hline Soriano e Mercedes & & $100 \%$ \\
\hline Total & & \\
\hline
\end{tabular}

Podemos, ainda, tentar uma aproximação pela ocupação dos campos por rebanhos. A média de criação das propriedades em que a dimensão e a quantidade de gado foram declaradas nos inventários é de $1.000 \mathrm{ca}-$ beças por légua. Pouco mais de 1\% (14) das propriedades tinha menos de uma légua de campo - equivalente a 4.356 hectares de área - o suficiente para criar ao menos 500 cabeças, o suficiente para sustentar uma família (Gelman, 1998, p. 85). Em 1856 foi produzida uma lista dos hacendados 
mais importantes de Cerro Largo e o cálculo aproximado do número de gado que cada um possuía. Dos 127 listados, 105 eram brasileiros, a grande maioria com rebanhos de mil a três mil bovinos (Zabiela, 2002, p. 146). Quando os dados dessa listagem foram cruzados com o RRNE, foi possível encontrar a dimensão de 46 propriedades. Analisando a média de ocupação a partir desses dois documentos, ela fica bem abaixo da apresentada nos inventários, com 343,54 animais por légua. Esse dado fica abaixo também das estimativas que o viajante francês Nicolau Dreys fez para as estâncias do Rio Grande do Sul. Segundo Dreys, “calcula-se que nas estâncias cada légua quadrada [4.356 hectares] pode receber e criar de 1.500 a 2.000 cabeças de gado" (Dreys, 1990, p. 66).

Muitos poderiam ser os fatores que influenciavam numa baixa da produtividade: dificuldade de encontrar trabalhadores para as lidas do campo, dificuldades para a retomada do crescimento dos rebanhos após a guerra, o crescimento progressivo de outras criações - especialmente a de ovinos (Winn, 1998, p. 78) -, epizootias e ataques de cães selvagens. De fato, na campanha rio-grandense, somente na década de 1860 apresentaram-se sinais de recuperação dos rebanhos, depois de quinze anos de paz e de uma diminuição das calamidades naturais (Bell, 1998, p. 80), não sendo improvável que o mesmo se verificasse na campanha oriental. Ainda assim, arrisco a opinar que possivelmente alguns proprietários tenham alegado rebanhos de menores dimensões por desconfiarem do responsável pela elaboração da lista, o comandante Dionísio Coronel, blanco, que durante a Guerra Grande foi frequentemente alvo de reclamações dos brasileiros estabelecidos em Cerro Largo. Porém, o fato de Coronel ter listado produtores com mais de mil cabeças de gado como os mais notáveis daquele departamento por si só constitui um importante corte para percebermos qual era o tamanho dos rebanhos que garantiam notoriedade social a seus proprietários.

Dos 46 estabelecimentos com dimensão identificada, 38 ficavam na faixa abaixo das cinco léguas, indicando que essa dimensão de propriedade era suficiente para classificar um produtor dentro de um grupo de elite.Ainda que essas sejam as posses menores dentro do RRNE, possuir entre uma e cinco léguas era o suficiente para garantir uma condição econômica favorecida, em que não apenas o rebanho tivesse condições de se reproduzir a ponto de garantir o exclusivismo da atividade. 
Tabela 3 - Propriedades segundo dimensões registradas no RRNE

\begin{tabular}{l|c|c}
\hline \multicolumn{1}{c|}{ Dimensões } & $\begin{array}{c}\text { NúmERO DE } \\
\text { PROPR IEDADES }\end{array}$ & PERCENTUAL \\
\hline Até 5 léguas (até 21.780 ha) & 689 & $50,88 \%$ \\
\hline Entre 6 e 9 léguas (de 26.136 a 39.204 ha) & 144 & $10,63 \%$ \\
\hline Entre 10 e 19 léguas (de 43.560 a 82.764 ha) & 97 & $7,16 \%$ \\
\hline Acima de 20 léguas (acima de 87.120 ha) & 44 & $3,24 \%$ \\
\hline Ignoradas & 380 & $28,6 \%$ \\
\hline Total & 1.354 & $100 \%$ \\
\hline
\end{tabular}

^ A conversão de medidas do período do Império, segundo o Ministério do Desenvolvimento Agrário, pretende uma légua como correspondente a $6.600 \mathrm{~m} 2$ ou 4.356 hectares.

De toda forma, o fato de $21,03 \%$ das propriedades listadas no RRNE - correspondendo a 29,26\% das propriedades com dimensão aponta$\mathrm{da}$ - terem capacidade de criar mais de cinco mil cabeças de gado é um dado que indica que essas não eram propriedades voltadas a subsistência, mas empreendimentos de médio e grande porte. Possivelmente esse número fosse maior se considerarmos que quase um terço das propriedades não tinha extensão declarada, e por outros documentos é possível averiguar que muitas delas tinham mais de 10 léguas.

Se observarmos esses dados matizados por região, veremos que, em relação às propriedades de menor tamanho a distribuição, eles se mantêm, apresentando pequenas alterações, porém em relação às propriedades de maior porte, a sua concentração na região de Tacuarembó parece ser bastante significativa, chegando a quase metade $(47,7 \%)$. Essa região ocupada maciçamente pelos brasileiros corresponde àquela área de ocupação indígena pacificada nos anos 1830 e que foi objeto de concessões dadas por Rivera e, depois, alvo da regularização fundiária por meio das denúncias de ocupação de terras públicas. Sua posição geográfica adjacente à fronteira seca do Upamarotim (a faixa de terras de mais de cem quilômetros entre o Brasil e o Uruguai próximo a Bagé, recortada por pequenos arroios e cerros), combinada à presença de tribos indígenas nômades e hostis, como os charruas, retardou a ocupação daquela área.

Tacuarembó apresentava uma baixíssima densidade populacional, o que aumentava o impacto da presença dos brasileiros. Segundo o censo geral de 1852, Tacuarembó contava com 6.567 almas, das quais 40,36\% 
eram estrangeiras, como indicado na Tabela 1 , sendo a esmagadora maioria de brasileiros. Antes disso, o único dado populacional que se tinha da região dava conta da existência de 500 habitantes em San Fructuoso - Ciudad de Tacuarembó, em 1837, ano da criação do departamento. Nas décadas de 1830 e 1840, segundo o estudo de Raquel Pollero (1990,p. 221-222), a população brasileira nesse departamento correspondia a 69,4\% e 59,7\%, respectivamente. Mesmo que os números tenham caído conforme avançava o século, em 1860 os brasileiros eram donos de 50\% dos bovinos de Tacuarembó (Zubillaga, 1977, p. 51).

A própria expansão da fronteira agrária no Rio Grande do Sul também acabou por ditar o ritmo da ocupação daquela região, que foi feita a partir de Jaguarão e Bagé. Essa era uma região entre as duas frentes mais antigas de ocupação do norte uruguaio pelos luso-brasileiros que correspondem às ocupações militares das primeiras décadas do século XIX (Borucki; Chagas; Stalla, 2004, p. 161).Ao contrário da frente de expansão no litoral, que ocupou Maldonado e depois Cerro Largo, acessível através do rio Jaguarão e da lagoa Mirim - além de ser parte do caminho para Montevidéu, tanto por terra quanto pela Atlântico -, ou da outra frente a oeste, aquela que ocupou o território entre o Arapehy e o Quaraí,junto à fronteira com a Argentina e acompanhou o fluxo do rio Uruguay, a ocupação de Tacuarembó não obedeceu a nenhum caminho fluvial próximo.

A essa combinação de fatores se juntaram outros. Nos anos 1830, com as dificuldades encontradas pelos charqueadores do Rio Grande do Sul e depois com a eclosão da Revolução Farroupilha - ela mesma relacionada diretamente a essas dificuldades -, alguns empresários do ramo buscaram se estabelecer nas proximidades de Montevidéu, levando parte do mercado de gado dos produtores rio-grandenses a se direcionar nesse sentido também. A possibilidade de aquisição de terras com títulos seguros e o menor preço da terra nas proximidades do rio Negro - inclusive na margem sul, no departamento de Durazno - atraiu investimentos altos. Das 33 propriedades de brasileiros listadas entres os rios Yí e Negro, ao sul deste último, doze têm mais de 20 léguas, representando mais de um terço de todas as estâncias de brasileiros da região e igualmente quase um terço das propriedades de grande porte do RRNE.

O verão de 1842-1843 foi marcado por uma grande seca na campanha oriental, que praticamente dizimou os rebanhos em grandes áreas 
da campanha. A reação do Gobierno del Cerrito foi proibir as faenas, ou seja, a marcação, venda e abate de gado em todo o território controlado pelo seu exército. Ainda, na província do Rio Grande do Sul, no ano anterior, uma grande peste tinha dizimado parte importante da produção bovina. Nos arredores de Montevidéu e em San José, os charqueadores rio-grandenses que tinham migrado seus negócios para o país vizinho, em busca de condições mais vantajosas fecharam seus estabelecimentos por conta da abolição da escravidão(que lhes retirou a mão de obra e parte do patrimônio), além da escassez de matéria prima.

E com isso, o mercado para os estancieiros brasileiros, que produziam num sistema baseado na mão de obra cativa e no extensivismo que exigia imensas propriedades monocultoras, voltaria a ter seu ponto de atração nas charqueadas de Pelotas, ou ao menos era o que pretendiam os charqueadores daquela cidade. Estava marcado o impasse que impediria que esses homens que viviam no norte se identificassem com as políticas pensadas para a República Oriental do Uruguai pelos sujeitos que buscavam ocupar os postos desde Montevidéu.

\section{Referências}

AITA, Edsiana Belgrado. Entre a lagoa e o mar: propriedade e mercado de terras em Santa Vitória do Palmar (1858-1888). Porto Alegre: UFR GS, 2014 (Dissertação de Mestrado em História).

AROCENA, Fernando. Regionalización cultural del Uruguay. Montevidéu: UDELAR/ Dirección Nacional de Cultura, 2011.

BARRÁN, José Pedro. Apogeo y crisis del Uruguay pastoril y caudillesco (1839-1875). Montevidéu: Ediciones de la Banda Oriental, 1990.

BARRÁN, José Pedro; NAHUM, Benjamin. História rural del Uruguay moderno (18511885). Montevidéu: Ediciones de la Banda Oriental, 1967.

BARRIOS PINTOS, Aníbal. Historia de los pueblos orientales. Montevidéu: Academia Nacional de Letras, 2000.

BELL, Stephen. Campanha gaúcha: a brazilian ranching system (1850-1920). Standford: Standford University Press, 1998.

BENTON, Lauren. The laws of this country: foreigners and the legal construction of sovereignty in Uruguay, 1830-1875. Law and History Review, v. 19, n. 3, p. 479-511, 2001.

BERTINO, Magdalena; MILLOT, Julio. Historia económica del Uruguay. Tomo I: Desde los orígenes hasta 1860. Montevidéu: Fundação de Cultura Universitária, 1991. 
BERUTE, Gabriel Santos. Atividades mercantis do Rio Grande de São Pedro: negócios, mercadorias e agentes mercantis (1808-1850). Porto Alegre: UFR GS, 2011(Tese de Doutorado em História).

BORUCKI, Alex; CHAGAS, Karla; STALLA, Natália. Esclavitud y trabajo: un estudio sobre los afrodescendientes en la frontera uruguaya (1835-1855). Montevidéu: Pulmón Ediciones, 2004.

CHASTEEN, J. C. Backgrounds of the civil war: the process of land tenure in Brazil's southern borderland (1801-1893). Hispanic American Historical Review, v. 71, n. 4, 1991.

DIAZ DE GUERRA, María A. História de Maldonado. Tomo I. Maldonado: Ed. Intendencia Municipal, 1988.

DREYS, Nicolau. Noticia descritiva da província do Rio Grande de São Pedro do Sul. Introdução e notas de Augusto Meyer. Porto Alegre: Instituto Estadual do Livro, 1961. (Original publicado em 1839)

FARINATTI, Luís Augusto E. Confins meridionais: famílias de elite e sociedade agrária na fronteira meridional do Brasil. Santa Maria: Editora da UFSM, 2010.

FAVRE, Oscar Padrón. Ocaso de un pueblo indio. Montevidéu: Editorial Fin de Siglo, 1996.

GARCIA, Graciela. O domínio da terra: conflitos e estrutura agrária na campanha rio-grandense oitocentista. Porto Alegre: UFR GS, 2005 (Dissertação de Mestrado em História).

GELMAN, Jorge. Campesinos y estancieiros. Una región del Rio de la Plata a fines de la época colonial. Buenos Aires: Editorial de los Libros del Riel, 1998.

GOLDMAN, Noemí; SALVATORE, Ricardo (Org.). Caudillismos rioplatenses. Buenos Aires: Eudeba, 1998.

KLEIN, Fernando. El destino de los indígenas del Uruguay. Nómadas: Revista Crítica de Ciencias Sociales y Jurídicas, v. 15, n. 1, 2007.

MAGARIÑOS DE MELLO, Mateo J. El gobierno del cerrito: colección de documentos oficiales emanados de los poderes del gobierno presidido por el brigadier general D. Manuel Oribe, 1843-1851. Poder ejecutivo, Tomo 1. Montevidéu: Imprenta El Siglo Ilustrado, 1948.

MENEGAT, Carla. O tramado, a pena e as tropas: família, política e negócios do casal Domingos José de Almeida e Bernardina Rodrigues Barcellos (Rio Grande de São Pedro, século XIX). Porto Alegre: UFRGS, 2009 (Dissertação de Mestrado em História).

MICHOELSSON, Omar E. Operativo San Fructuoso. Tacuarembó: 1990.

MONQUELAT, A. F. Senhores da carne: charqueadores, saladeristas y esclavistas. Pelotas: Ed. Universitária/UFPel, 2010.

NAHUM, Benjamin. História Rural del Uruguay moderno (1851-1885). Montevidéu: Ediciones de la Banda Oriental, 1967.

OSÓRIO, Helen. O império português no sul da América: estancieiros, lavradores e comerciantes. Porto Alegre: Editora da UFRGS, 2007. 
POLLERO, Raquel. Estudio de la población de Tacuarembó en base a datos histórico-demográficos.VII Encuentro Nacional yV Regional de Historia, Anales..., n. 2, p. 221-222, Montevidéu, out. 1990.

PETRISSANS, Ricardo; FREIRÍA, Gonçalo. Extranjerización de las tierras nacionales. Montevidéu: Proyeccion, 1987.

RILLA, José. La tradición contra los partidos en el Uruguay. História, Franca, v. 23, n. 1-2,2004.Disponível em:<http://dx.doi.org/10.1590/S0101-90742004000200009>. Acesso em: 11 maio 2020.

SOUZA, Susana Bleil de; PRADO, Fabrício Pereira. Brasileiros na fronteira uruguaia: economia e política no século XIX. In: GRIJÓ, Luiz A.; KUHN, Fábio; GUAZZELLI, César A. B.; NEUMANN, Eduardo. Capítulos de história do Rio Grande do Sul. Porto Alegre: Editora da UFRGS, 2004.

TOURON, Lucía Sala de; ELOY, Rosa Alonso. El Uruguay comercial, pastoril y caudilhesco. Montevidéu: Ediciones de La Banda Oriental. 1986.

VAR GAS, Jonas Moreira. Pelas margens do Atlântico: um estudo sobre elites locais e regionais no Brasil a partir das famílias proprietárias de charqueadas em Pelotas, Rio Grande do Sul (século XIX). Rio de Janeiro: UFRJ, 2013 (Tese de Doutorado em História).

WINN, Peter. Inglaterra y Tierra Púrpurea. Tomo I. Montevidéu: Facultad de Humanidades y Ciências de la Educación (UDELAR), 1997.

YOUNGER, Joseph. Corredores de comércio e salas de justiça: lei, coerção e lealdade nas fronteiras do Rio da Prata. Revista Aedos, v. 1, n. 1, p. 290-311, 2008.

ZABIELA, Eliane. A presença brasileira no Uruguai e os tratados de 1851 de comércio e navegação, de extradição e de limites. Porto Alegre: UFRGS, 2002 (Dissertação de Mestrado em História).

ZUBILLAGA, Carlos. Algunos antecendentes sobre acondicionamento territorial em Uruguay (1611-1911). Cuadernodel CLAEH, Montevidéu, n. 4, p. 37-61, 1977. 